\title{
Development of Japanese Versions of the Control Preferences Scale and Information Needs Questionnaire: Role of Decision-Making and Information Needs for Japanese Breast Cancer Patients
}

\author{
Kanako Azuma' \\ Takashi Kawaguchi $\mathbb{D D}^{2}$ \\ Takuhiro Yamaguchi ${ }^{3}$ \\ Sayuri Motegi' \\ Kimito Yamada ${ }^{4}$ \\ Kenji Onda ${ }^{5}$ \\ Satoru Iwase ${ }^{6}$ \\ Sakae Unezaki ${ }^{2}$ \\ Hironori Takeuchi' \\ 'Department of Pharmacy, Tokyo Medical \\ University Hospital, Tokyo, Japan; \\ ${ }^{2}$ Department of Practical Pharmacy, \\ School of Pharmacy, Tokyo University of \\ Pharmacy and Life Sciences, Tokyo, Japan; \\ ${ }^{3}$ Division of Biostatistics, Tohoku \\ University Graduate School of Medicine, \\ Miyagi, Japan; ${ }^{4}$ Department of Breast \\ Surgery, Tokyo Medical University \\ Hospital, Tokyo, Japan; ${ }^{5}$ Department of \\ Clinical Pharmacology, School of \\ Pharmacy, Tokyo University of Pharmacy \\ and Life Sciences, Tokyo, Japan; \\ ${ }^{6}$ Department of Emergency \& Palliative \\ Medicine, Faculty of Medicine, Saitama \\ Medical University, Saitama, Japan
}

Correspondence: Takashi Kawaguchi

Email tkawa@toyaku.ac.jp
Purpose: The importance of shared decision-making (SDM) between physicians and patients is increasingly recognized. In Japan, patients have shown more willingness to participate in treatment if medical professionals provide sufficient information; however, relationships between physicians and patients have traditionally been asymmetric, with patients accepting information from physicians without discussion. To explore the benefits of SDM in cancer treatment, including confidence in treatment decisions, satisfaction with treatment, and trust in healthcare providers, this study developed Japanese versions of the Control Preference Scale (CPS) and Information Needs Questionnaire (INQ).

Patients and Methods: Reliability and validity of the CPS and INQ were tested with 49 breast cancer patients.

Results: The CPS showed good test-retest reliability (kappa coefficient: 0.61, weighted kappa coefficient: 0.61 , Kendall's tau coefficient: 0.61 ) and acceptable criterion validity. The INQ showed adequate consistency; the mean number of circular triads and coefficient of consistency were 3 (range 0-19) and 0.9 (range 0.37-1), respectively. Using the CPS and INQ to identify patients' roles in decision-making and information needs, results further suggested that breast cancer patients in Japan want to participate in SDM. Medical issues, including disease spread and cure, were found to be of high interest, while social and psychological issues, including sexual attractiveness, genetic risk, and family impact, tended to be low.

Conclusion: The Japanese CPS and INQ can be used to assess patients' needs to improve care. Further, as patients' information needs change along the care trajectory, these tools should be used throughout treatment.

Keywords: shared decision-making, breast cancer, treatment option, control preference scale, information needs questionnaire

\section{Introduction}

Shared decision-making (SDM) is a collaborative model for making medical decisions, including multiple medical treatment options, between healthcare professionals and patients. ${ }^{1}$ Cancer patients need to make informed decisions regarding complex diagnoses, treatment options, treatment side effects, and the impact of treatment on both quality of life and longevity. ${ }^{2} \mathrm{SDM}$ in cancer treatment may have 
multiple benefits. Cancer patients who are involved in healthcare decisions are more likely to experience confidence in treatment decisions, satisfaction with treatment, and trust in healthcare providers. ${ }^{3,4}$ Patients vary in their preferred levels of participation in cancer treatment decision-making; patient characteristics such as age, sex, race/ ethnicity, cancer type, and individual values and beliefs may affect these preferences. ${ }^{5-8}$ Older patients may prefer a more passive role. ${ }^{9}$ Women are more likely to report a passive role in cancer treatment decisions than men; however, they tend to demonstrate less agreement between actual and preferred roles in decision-making. ${ }^{6}$ There are fewer reports of patient decisions made in non-Western countries than in Western countries. It is difficult to compare the extant research because no common scale is used, but overall, results suggest that Asian patients desire a negative or collaborative role in decision-making. ${ }^{10}$ Reasons for this include beliefs concerning doctor-patient relationships (patients recognize that their knowledge of treatment is inferior to that of doctors), family support (patients want to consider the impact on their family and compare options with their family), and low education levels. ${ }^{10}$ In Japan, the traditional communication style of paternalism has tended to be expressed through asymmetrical relationships between physicians and patients. Medical experts' diagnostic evaluations were viewed as more or less indisputable, and patients seeking help and care had to accept these experts' decisions without discussion. $^{11}$ Slingsby described decision-making in Japan as an "omakase (entrusting) model"; however, there has been a shift from passive to active decisionmaking. ${ }^{12}$ A study by Watanabe reveals that the decisionmaking roles preferred by Japanese cancer patients vary from doctor-centered to patient-centered roles. ${ }^{13}$ A correlation between patient preferences for roles in the decision-making process and the level of actual decisionmaking involvement has been shown to be an indicator of patient satisfaction, which was independent of who made the final decision; moreover, this finding is compatible with other studies conducted in the United States. ${ }^{13}$

The Control Preferences Scale (CPS) has been widely used in research with people facing life-threatening medical decisions. ${ }^{14}$ The CPS was originally developed by Degner et al. ${ }^{14}$ The control preferences construct is defined as "the degree of control an individual wants to assume when decisions are being made about medical treatment". 14 The CPS uses five response statements to measure the patient's role in decision-making. Two statements represent an active role, one a collaborative role; and two a passive role. The CPS can be used to examine the role of decision-making for various cancer types, especially breast and prostate cancer. ${ }^{15-19}$ However, there is currently no Japanese version of the CPS, a scale that is widely used to classify roles in decision-making and is internationally comparable.

Providing information and making decisions together is increasingly recognized as an important element of caregiving. ${ }^{20}$ Information is necessary for patients to understand their conditions and make decisions regarding treatment. However, physicians often underestimate patients' desire for information. ${ }^{21}$ Providing information in cancer treatment is regarded as one standard of care and is considered a therapeutic intervention. ${ }^{22}$ Several studies have shown that most cancer patients want a maximum of detailed information, whether it is good or bad. ${ }^{23,24}$ It has further been suggested that cancer patients' information needs can change over the course of treatment. From diagnosis to the start of treatment, patients consider information such as disease stage, treatment options, and side effects to be important. However, after starting treatment, patients attach importance to information on treatment and subsequent recovery. ${ }^{25,26}$ It has been shown that patients tend be more active in treatment decisions if medical professionals provide sufficient information. ${ }^{27}$ Research has also shown that patients' information needs can differ according to cancer type, and the information provided must meet these needs. ${ }^{28}$

Cancer patients' information needs can be studied using various measurement tools, such as the Information Needs Questionnaire (INQ), ${ }^{18}$ the Toronto Information Needs Questionnaire-Breast Cancer (TINQ-BC), ${ }^{29}$ and the Patient Learning Needs Scale (PLNS). ${ }^{30}$ The INQ is a differential scale, which allows for comparisons of changes in an individual's position on dimensions, or for comparisons across individual differences relative to the dimension, while the TINQ-BC and PLNS are summative scales. ${ }^{31,32}$

Recently, pharmacists' roles have expanded from only supplying medications to providing information, education, and pharmaceutical care to patients. $^{33}$ Particularly, a pharmacist's role of providing information is not limited to explaining the effects of treatment and adverse events but also has a wide range of effects on patients' daily lives and families. Studies have shown that information from pharmacists improves adherence, therapeutic efficacy, and satisfaction with drug treatment. ${ }^{34-37}$ It is important to share information between medical professionals and patients; ${ }^{38}$ however, there is no internationally comparable evaluation method in Japan. Therefore, by developing Japanese versions 
of the CPS and INQ, explanations regarding medications could be provided considering patients' individualized information needs. The aim of the present study was twofold. First, the purpose of this study was to develop Japanese versions of the CPS, which evaluates patients' roles in decision-making regarding treatment, and the INQ, which evaluates patients' information needs. Further, this study evaluated the test-retest reliability and criterion validity of the CPS and the consistency of the INQ. Second, we aimed to clarify the difference between the roles that patients prefer and play in treatment decisions using the Japanese version of CPS. We also aimed to evaluate the information needs of breast cancer patients using the Japanese version of INQ.

\section{Patients and Methods}

\section{Translation Procedure}

The original versions of the CPS and INQ are available in English. ${ }^{14,18,39}$ We received permission from the developers of the CPS and INQ to create our translated versions. The Japanese versions were translated into Japanese using the forward-backward translation method. ${ }^{40}$ First, two native Japanese speakers conducted the forward translation. One of the translators was informed of the aim and concept of the questionnaire, but the other was not. After the translations of both of the translators were synthesized, two translators back-translated the synthesized questionnaire into English. The two latter translators were native English language professionals without a medical background and were not informed of the aim or concept of the questionnaire. A committee comprised of the developer of the English version, the research director, a linguist, a statistician, and the four translators discussed the semantic, empirical, and conceptual equivalence, and created a Japanese pilot version. A pilot study was conducted to identify and solve potential problems with the pilot version. In the pilot study, after conducting a structured interview with five patients, the committee discussed problems and created the final Japanese versions of the CPS and INQ.

\section{Instruments}

\section{Control Preference Scale}

The CPS consists of five cards on a board, each using a cartoon and short descriptive statement to illustrate a different role in decision-making. ${ }^{14}$

The items are as follows:

A: I prefer to make the final selection about which treatment I will receive.
B: I prefer to make the final selection of my treatment after seriously considering my doctor's opinion.

C: I prefer that my doctor and I share responsibility for deciding which treatment is best for me.

D: I prefer that my doctor makes the final decision about which treatment will be used, but seriously considers my opinion.

E: I prefer to leave all decisions regarding my treatment to my doctor.

\section{Information Needs Questionnaire}

The INQ in an instrument designed to measure the priority of information needs for breast cancer patients using the Thurstone method of pair comparisons. ${ }^{18}$ The version of the INQ used in our research was revised to accommodate not only breast cancer patients but also other cancer patients and includes nine items related to important information for cancer patients. ${ }^{39}$

The items are as follows:

1. Information about how advanced the disease is and how far it has spread. (Spread of Disease)

2. Information about the likelihood of cure from the disease. (Cure)

3. Information about how treatment may affect my ability to carry on my usual social activities (eg, hobbies, sports, etc.). (Social Life)

4. Information about how my family and close friends may be affected by the disease. (Family Impact)

5. Information about caring for myself at home (eg, diet, support groups, help at home, social worker, counselor). (Self-Care)

6. Information about how the treatment may affect my feelings about my body and sexual attractiveness. (Sexual Attractiveness)

7. Information about the different types of treatment and their advantages and disadvantages. (Treatment)

8. Information about whether my children or other members of my family are at risk of getting the disease. (Genetic Risk)

Information about possible side effects of treatment. (Side Effects)

\section{Procedure}

\section{Control Preference Scale}

The researcher asked the participants to arrange in order the five cards of the Japanese version of CPS depicting the 
patient's actual role and most preferred role regarding the treatment they are currently receiving. When the patient finishes this ranking, the researcher can assign the patient one of the following six classifications, based on the top two chosen cards: active-active, active-collaborative, collaborative-active, collaborative-passive, passive-collaborative, and passive-passive. According to these classifications, patients are then divided into three groups: active (active-active or active-collaborative), collaborative (collaborative-active or collaborative-passive), or passive (passive-collaborative or passive-passive). Subsequently, a semi- structured interview was conducted, in which the participants were asked the following four questions:

1. Currently, you have decided [interviewer states the present treatment]. How did you make this decision?

2. Why did you make this decision?

3. The interviewer then summarized the respondent's main decision criteria and probed for other potential reasons for the decision.

4. Did you share this information with your doctor? (Yes/No; Why/Why not)

Interview results were documented using an IC recorder. After two to four weeks, the same patient was readministered with CPS to measure the patient's actual role.

\section{Information Needs}

The researcher created a total of 36 pairs $(n(n-1) / 2)$, which paired each of the nine items of INQ. The researchers asked patients which was more important and requested that they choose one of two. Patients responded using a tablet computer.

\section{Participants}

This study was conducted with breast cancer patients who visited Tokyo Medical University Hospital and the Nagumo clinic from August to November 2013. Eligibility criteria were as follows: women between the ages of 20, the age of adulthood in Japan, to 75 due to consideration of cognitive function, diagnosed with breast cancer, and receiving chemotherapy or endocrine therapy. Participants were asked to fill out the questionnaire after at least one month since the start of treatment. Patients who had a serious mental health disorder were excluded. The sample size was set to 50 based on the feasibility of the study period rather than on a statistical basis.

\section{Measurement and Statistical Analysis Demographics}

Researchers collected data from participants' medical records regarding age, metastasis, current treatment, type of therapy, and history of treatment. Participants completed a questionnaire on marital status, education level, employment status, and household composition. Proportions and standard deviations $(S D)$ were calculated for age, metastasis, current therapy, type of therapy, history of treatment, marital status, education level, and household employment status.

\section{Control Preference Scale}

To assess test-retest reliability, the kappa coefficient and Kendall's tau coefficient were calculated from two measurements of the patient's actual role. To assess the scale's criterion-related validity, we asked each of the four researchers to evaluate the patient's decision-making based on the results of the structured interview, using the CPS and Charles' model. ${ }^{41}$ Charles' model classified the decision-making process into three types: paternalistic, shared, and informed approaches. The kappa coefficient and Kendall's tau coefficient were evaluated based on the CPS evaluation of the actual role played by the patient and information obtained from the patient's interview, based on the four researcher's evaluation using the CPS and Charles' model. The degree of agreement between the patient's preferred and actual roles, as evaluated using the CPS, was calculated using the kappa coefficient and Kendall's tau coefficient.

\section{Information Needs}

To evaluate the construct validity of the INQ, the coefficient of consistency, which indicates whether the individual was ranked among the items, was calculated from the number of circular triads. The coefficient of consistency indicates whether the ranking among individual items is made when comparing three or more items and is calculated with a value of $0-1$. The higher the value of the coefficient of consistency, the smaller the number of circular triads, indicating the evaluation is consistent.

We defined the Japanese version of the INQ to be considered adequately valid if the coefficient of consistency was greater than $0.5 .^{42}$ Additionally, the selection ratio of each item was calculated in order to determine the 
status of patients' selection for each question item. The higher the selection ratio, the more important the information related to that item is to the patient. The scale value of each item was calculated by the Thurstone method using the selection ratio and visualized, and the relative positional relationship of the importance of items was determined. However, pairwise comparisons of the Thurstone method cannot be calculated when the selection ratio for each pair is 0.0 or 1.0. In that case, we made calculations by replacing 0.0 with 0.01 and 1.0 with 0.99 .

\section{Results}

\section{Participants}

Five patients participated in the pilot study and 50 patients participated in this study from August to November 2013. We excluded the data of one patient from analysis due to withdrawal of consent. Thus, a total of 49 participants who completed the Japanese versions of the CPS and INQ were included in the analysis. Participant characteristics are shown in Table 1. Mean participant age was $52.4(S D=$ 9.0 ), and $26.5 \%$ of participants had metastatic cancer. Regarding current treatment, $67.3 \%$ of patients were receiving chemotherapy, $32.7 \%$ were receiving endocrine therapy, and $73.5 \%$ were receiving a type of adjuvant therapy. Additionally, $77.6 \%$ of the patients had a high educational level, while $22.4 \%$ had a medium level of education.

\section{Test-Retest Reliability of the CPS}

Table 2 shows the results of patients' CPS ratings on the first and second evaluations for their actual roles in decision-making. Regarding reliability, the kappa coefficient was 0.61 (95\% CI: $0.40-0.82)$, the weighted kappa coefficient was 0.61 (95\% CI: 0.39-0.83), and Kendall's tau coefficient was 0.61 (95\% CI: $0.38-0.83)$. If the value exceeds 0.6 , the degree of coincidence can be assumed to be high. Thus, the Japanese version of the CPS was determined to have good reliability.

\section{Criterion-Related Validity of the CPS}

The four researchers evaluated the patients' decisionmaking based on the results of the structured interview, using the CPS and Charles' model. Regarding criterion validity, the weighted kappa coefficients for Researchers 1 and 2 were 0.33 (95\% CI: $0.10-0.57)$ and 0.44 (95\% CI: 0.25-0.63) in the CPS ratings. In the Charles' model rating, the weighted kappa coefficients for Researchers 3 and 4 were 0.40 (95\% CI: $0.17-0.63)$, and 0.39 (95\% CI:
Table I Participant Characteristics in the Study Sample $(N=49)$

\begin{tabular}{|c|c|c|}
\hline & Mean & SD \\
\hline Age & $\begin{array}{l}51.9 \\
n\end{array}$ & $\begin{array}{l}9.0 \\
\%\end{array}$ \\
\hline \multicolumn{3}{|l|}{ Metastasis } \\
\hline Yes & 13 & 26.5 \\
\hline No & 36 & 73.5 \\
\hline \multicolumn{3}{|l|}{ Current therapy } \\
\hline Endocrine therapy & 16 & 32.7 \\
\hline Chemotherapy & 33 & 67.3 \\
\hline \multicolumn{3}{|l|}{ Type of therapy } \\
\hline Adjuvant & 36 & 73.5 \\
\hline Palliative & 13 & 26.5 \\
\hline \multicolumn{3}{|l|}{ History of treatment } \\
\hline None & 16 & 32.7 \\
\hline Chemotherapy & 24 & 49.0 \\
\hline Endocrine therapy & 3 & 6.1 \\
\hline Both & 6 & 12.2 \\
\hline \multicolumn{3}{|l|}{ Marital status } \\
\hline Married & 36 & 73.5 \\
\hline Unmarried & 10 & 20.4 \\
\hline Other & 3 & 6.1 \\
\hline \multicolumn{3}{|l|}{ Educational level } \\
\hline High & 11 & 22.4 \\
\hline Middle & 38 & 77.6 \\
\hline \multicolumn{3}{|l|}{ Employment status } \\
\hline Full-time & 15 & 30.6 \\
\hline Part-time & 13 & 26.5 \\
\hline Housekeeper & 20 & 40.8 \\
\hline Unemployed or retired & 1 & 2.0 \\
\hline \multicolumn{3}{|l|}{ Household } \\
\hline Living with a partner & 35 & 71.4 \\
\hline Living alone & 10 & 20.4 \\
\hline Other & 4 & 8.2 \\
\hline
\end{tabular}

Abbreviation: SD, standard deviation.

0.19-0.59) (Table 3). The assessment of the role patients actually played, and the documentation of the patients' interviews conducted by the researchers did not show a high degree of agreement.

\section{Preferred Role and Actual Role of the Patient}

Patients' actual roles often did not match their preferred roles. In total, $39.6 \%$ of participants reported they wanted a passive role in decision-making, while 
Table 2 Results of the CPS Assessment of Patients' Actual Roles ( $N=48)$

\begin{tabular}{|c|c|c|c|c|}
\hline & \multicolumn{4}{|c|}{ First Patient Evaluation } \\
\hline & n (\%) & Active & Collaborative & Passive \\
\hline \multirow{4}{*}{ Second patient evaluation } & Active & $8(16.7)$ & $2(4.2)$ & I (2.I) \\
\hline & Collaborative & $0(0)$ & $4(8.3)$ & I (2.I) \\
\hline & Passive & $5(10.4)$ & I (2.I) & $26(54.2)$ \\
\hline & Total & $13(27.1)$ & $7(14.6)$ & $28(58.3)$ \\
\hline
\end{tabular}

Notes: The abscissa shows the first CPS assessment of patients, and the ordinate shows the result of re-measurement.

$58.3 \%$ actually played a passive role (Table 4). As a result, the kappa coefficient was 0.23 (95\% CI: 0.04-0.43), the weighted kappa coefficient was 0.31 (95\% CI: 0.09-0.52), and Kendall's tau coefficient was 0.35 (95\% CI: $0.18-0.58)$.

\section{Construct Validity of the INQ}

The median number of circular triads and the coefficient of consistency were 3 (range $0-19$ ) and 0.9 (range 0.37-1), respectively, for 48 patients. We adopted the cutoff value of $>0.5$ for the coefficient of consistency. For one patient, the number of circular triads was 19, and the coefficient of consistency was 0.37 , which was lower than 0.5 . Therefore, this patient's data were excluded. As a result, the Japanese version of the INQ was considered to have adequate consistency.

\section{Information Needs}

The results of the paired comparisons are presented in Figure 1. One patient who did not have an adequate coefficient of consistency was excluded from analysis. For participants, medical issues such as spread of the disease and cure were found to be of high interest, while social and psychological issues tended to be of low interest.

\section{Discussion}

We developed Japanese versions of the CPS and INQ and investigated breast cancer patients' roles in decisionmaking regarding their treatment and information needs. The Japanese version of the CPS showed good test-retest reliability and acceptable criterion validity. Thus, our results showed that the Japanese version of the CPS could be used to assess patients' roles in decisionmaking. The Japanese version of the INQ was found to

Table 3 Degrees of Agreement Between Patients' and Researchers' Evaluations

\begin{tabular}{|c|c|c|c|c|}
\hline & \multicolumn{2}{|l|}{ CPS } & \multicolumn{2}{|l|}{ Charles' Model } \\
\hline & Researcher I & Researcher 2 & Researcher 3 & Researcher 4 \\
\hline Kappa coefficient $(95 \% \mathrm{Cl})$ & $0.35(0.14-0.55)$ & $0.37(0.19-0.55)$ & $0.43(0.22-0.63)$ & $0.4 I(0.3 I-0.92)$ \\
\hline Weighed kappa statistic $(95 \% \mathrm{Cl})$ & $0.33(0.10-0.57)$ & $0.44(0.25-0.63)$ & $0.40(0.17-0.63)$ & $0.39(0.19-0.59)$ \\
\hline Kendall tau coefficient $(95 \% \mathrm{Cl})$ & $0.32(0.05-0.58)$ & $0.50(0.30-0.70)$ & $0.42(0.17-0.67)$ & $0.40(0.18-0.63)$ \\
\hline
\end{tabular}

Table 4 Degrees of Agreement Between Patients' Actual and Preferred Decision-Making Roles

\begin{tabular}{|c|c|c|c|c|c|}
\hline & \multicolumn{5}{|c|}{ Actual Role } \\
\hline & n (\%) & Active & Collaborative & Passive & Total \\
\hline \multirow{4}{*}{ Preferred role } & Active & $6(12.5)$ & $2(4.2)$ & $4(8.3)$ & $12(25.0)$ \\
\hline & Collaborative & $5(10.4)$ & $3(6.3)$ & $9(18.8)$ & $17(35.4)$ \\
\hline & Passive & $2(4.2)$ & $2(4.2)$ & $15(3 \mid .3)$ & $19(39.6)$ \\
\hline & Total & $13(27.1)$ & $7(14.6)$ & $28(58.3)$ & \\
\hline
\end{tabular}




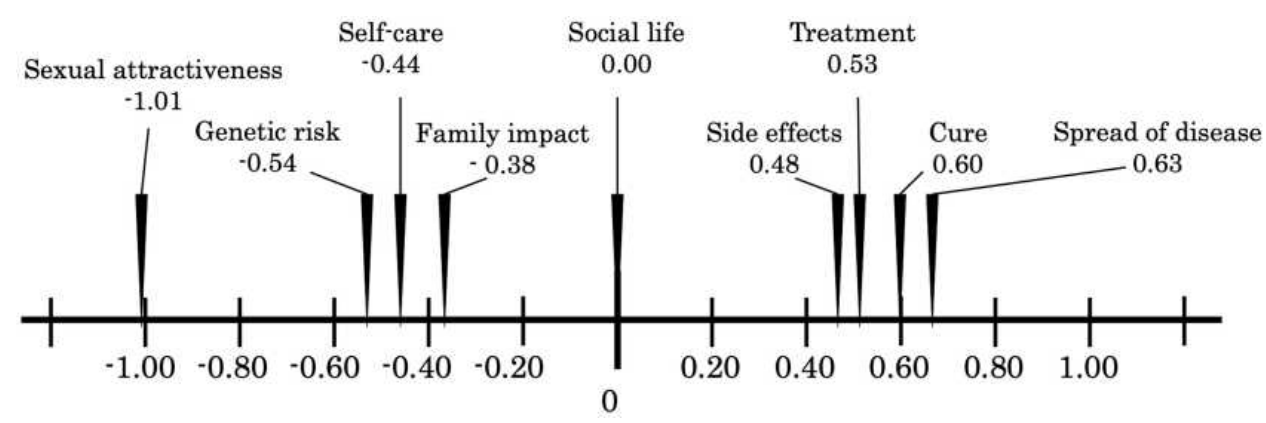

Figure I Information needs of breast cancer patients $(N=49)$.

be highly consistent and could be used to assess patients' information needs.

In examining the validity of the Japanese version of the CPS, the degree of agreement between patients and researchers was not high. A structured interview was recorded and documented. We considered the reason for the lack of a high degree of agreement to be because documenting interviews with patients made it difficult for researchers to assess the unique ways pauses were used when participants were hesitant or anxious about answering a question, or ambiguous expressions in spoken Japanese conversations, as these cannot be included in audio recording.

The actual roles patients played, as determined by CPS assessment, did not match their preferred roles. More than $70 \%$ of participants received adjuvant therapy, suggesting that physicians may not have provided enough information for patients to have options, for example no treatment, other than adjuvant therapy. Therefore, it is presumed there were many patients who considered treatment policy to be something mainly decided by their doctor. However, our results suggested that breast cancer patients want to make more collaborative decisions with their doctors regarding treatment. Previous studies in Canada and Sweden also showed that breast cancer patients prefer a less passive decision-making role. ${ }^{14,43}$

The Japanese version of the INQ was highly consistent; however, in one patient, the coefficient of consistency was 0.37 , indicating inconsistent ranking of information needs. The cause of the increase in the number of circular triads was considered to be the similarity of the notation in each question item and individual differences among patients' demographic and clinical characteristics. ${ }^{44}$ Focusing on the similarity of the notation in each question item, it is considered that all nine items were not difficult to distinguish, because each item was created from nine different areas. Explanations were added for each question item, however, when patients provided answers, in some instances similar kanji were presented in pairs on the tablet computer, such as those for "healing" and "treatment." In such cases, it is possible that patients may have mistaken the words for synonyms.

Regarding individual differences among patients, it has been reported that age, educational level, family history, and time since diagnosis affect the number of circular triads and the coefficient of consistency, which valuating item of consistency. ${ }^{44}$ Patients who are highly educated or who have had a long period of time pass since diagnosis tend to be able to fully understand their own health conditions and information needs and can thus distinguish between and order the nine items. We did not examine relevance to the patient's demographic factors when evaluating validity. Therefore, it would be necessary to examine the relevance of more demographic factors in the future. It was suggested that the most important information for patients was regarding prognosis, such as spread of the disease, cure, treatment, and side effects. In the scale values depicted, a large difference was observed between the top four items and the bottom five items. The findings suggested that many participants were receiving adjuvant therapy, and that remission or full remission was the goal of treatment. Participants also indicated a high need for information on social life, and differences were found between the preceding and following items. In a study conducted in Canada, the most important item was cure, followed by spread of the disease, treatment, and genetic risks, side effects, family impact, social life, self-care, and sexual attractiveness. ${ }^{32}$ Compared to our findings, previous studies indicated that patients placed more importance on information regarding genetic risk. Japanese breast cancer patients' BRCA1/2 mutation rates are similar to those in Europe and the United States. ${ }^{45}$ However, at the time this study was conducted, genetic testing in Japan was not covered by insurance. Therefore, 
the test implementation rate was overwhelmingly lower than in Canada. For this reason, medical information regarding genetic risk was most likely not widely provided; thus, patients' recognition of this information was insufficient.

Previous studies have shown that medication counseling provided by pharmacists reduces patients' decision-making conflicts. $^{46}$ The most important aspect of pharmacist drug counseling is the quality of the information provided, and patients want accurate and thoughtful information. ${ }^{47}$ The Japanese versions of the CPS and INQ developed in this study could be used to evaluate the role of patients' decisionmaking and information needs regarding treatment for various types of cancer, and to support patient decision-making. We believe that intervention from pharmacists, with consideration for each patient, can be implemented to support patients' decision-making processes.

\section{Limitations}

The number of patients studied in this research is small. In addition, patients with varying characteristics, such as time from diagnosis, time from the start of drug treatment, and different stages of cancer, were included. In the future, it will be necessary to increase the number of patients and further examine each patient's background regarding their preferred role, actual role, and information needs in decision-making.

\section{Conclusion}

We developed Japanese versions of CPS and INQ. We believe that these versions can support patient decisionmaking and contribute to improving patients' treatment satisfaction by clarifying the decision-making role and information needs of Japanese cancer patients. Furthermore, it is expected that research on the decision-making of Japanese cancer patients will be promoted and international comparison will be possible.

\section{Abbreviations}

CI, Confidence Interval; CPS, Control Preference Scale; INQ, Information Needs Questionnaire; PLNS, Patient Learning Needs Scale; SD, Standard Deviation; SDM, Shared Decision-making; TINQ-BC, Toronto Information Needs Questionnaire-Breast Cancer.

\section{Data Sharing Statement}

Not applicable.

\section{Ethics Approval and Informed Consent}

This study was conducted in accordance with the Japanese Ethical Guidelines for Epidemiological Research and the World Medical Association's Declaration of Helsinki. The Japanese Ethical Guidelines for Epidemiological Research were revised in 2014. The case collection for this study was conducted prior to revision and is based on old ethical guidelines. Written informed consent was obtained from all patients. The protocol was approved by the institutional review board of Tokyo Medical University and Nagumo clinic. This study is registered at UMIN-CTR, number UMIN000011272.

\section{Consent for Publication}

Not applicable.

\section{Acknowledgments}

We acknowledge and thank our collaborators for their thoughtful contribution to the conduct of this study (Thomas F Hack, Tomoyo Yamanaka, Eric M Skier, Tadaharu Matsunaga, Megumi Umeda, Hiroshi Kaise, Takashi Ishikawa, Hideaki Ayuhara, and Takao Akashi).

\section{Author Contributions}

All authors made substantial contributions to conception and design, acquisition of data, or analysis and interpretation of data; took part in drafting the article or revising it critically for important intellectual content; agreed to submit to the current journal; gave final approval of the version to be published; and agree to be accountable for all aspects of the work.

\section{Funding}

There is no funding to report.

\section{Disclosure}

The authors declare that there are no competing interests.

\section{References}

1. Politi MC, Studts JL, Hayslip JW. Shared decision making in oncology practice: what do oncologists need to know? Oncologist. 2012;17:91-100. doi:10.1634/theoncologist.2011-0261

2. Arora NK. Interacting with cancer patients: the significance of physicians' communication behavior. Soc Sci Med. 2003;57(5):791-806. doi:10.1016/S0277-9536(02)00449-5

3. Fowler FJ Jr, Gallagher PM, Drake KM, Sepucha KR. Decision dissonance: evaluating an approach to measuring the quality of surgical decision making. Jt Comm J Qual Patient Saf. 2013;39:136-144. doi:10.1016/s1553-7250(13)39020-5 
4. Arora NK, Weaver KE, Clayman ML, Oakley-Girvan I, Potosky AL. Physicians' decision-making style and psychosocial outcomes among cancer survivors. Patient Educ Couns. 2009;77(3):404-412. doi:10.1016/j.pec.2009.10.004

5. Fallowfield LJ. Treatment decision-making in breast cancer: the patient-doctor relationship. Breast Cancer Res Treat. 2008;112:5-13. doi:10.1007/s10549-008-0077-3

6. Singh S, Butow P, Charles M, Tattersall MHN. Shared decision making in oncology: assessing oncologist behavior in consultations in which adjuvant therapy is considered after primary surgical treatment. Health Expect. 2010;13:244-257. doi:10.1111/j.13697625.2009.00587.x

7. Mead EL, Doorenbos AZ, Javid SH, et al. Shared decision-making for cancer care among racial and ethnic minorities: a systematic review. Am J Public Health. 2013;103:e15-e29. doi:10.2105/ AJPH.2013.301631

8. Obeidat RF, Homish GG, Lally RM. Shared decision making among individuals with cancer in non-Western cultures: a literature review. Oncol Nurs Forum. 2013;40(5):454-463. doi:10.1188/13.ONF.454-463

9. Institute of Medicine. Delivering High-Quality Cancer Care: Charting a New Course for a System in Crisis. Washington, DC: The National Academies Press; 2013.

10. Yilmaz NG, Schouten BC, Schinkel S, van Weert JCM. Information and participation preferences and needs of non-Western ethnic minority cancer patients and survivors: a systematic review of the literature. Patient Educ Couns. 2019;102(4):631-650. doi:10.1016/j. pec.2018.11.018

11. Nomura K, Ohno M, Fujinuma Y, Ishikawa H. Patient autonomy preferences among hypertensive outpatients in a primary care setting in Japan. Intern Med. 2007;46:1403-1408. doi:10.2169/ internalmedicine.46.0141

12. Slingsby BT. Decision-making models in Japanese psychiatry: transitions from passive to active patterns. Soc Sci Med. 2004;59:83-91. doi:10.1016/j.socscimed.2003.10.006

13. Watanabe Y, Takahashi M, Kai I. Japanese cancer patient participation in and satisfaction with treatment-related decision-making a qualitative study. BMC Public Health. 2008;27(8):77. doi: 10.1186/1471-2458-8-77

14. Degner LF, Sloan JA, Venkatesh P. The Control Preferences Scale. Can J Nurs Res. 1997;29:21-43.

15. Davison BJ, Degner LF. Empowerment of men newly diagnosed with prostate cancer. Cancer Nurs. 1997;20:187-196. doi:10.1097/ 00002820-199706000-00004

16. Hack TF, Pickles T, Bultz BD, Ruether JD, Degner LF. Impact of providing audiotapes of primary treatment consultations to men with prostate cancer: a multi-site, randomized, controlled trial. Psychooncology. 2007;16:543-552. doi:10.1002/pon.1094

17. Hack TF, Pickles T, Bultz BD, et al. Impact of providing audio-tapes of primary adjuvant treatment consultations to women with breast cancer: a multisite, randomized, controlled trial. J Clin Oncol. 2003;21(22):4138-4144. doi:10.1200/JCO.2003.12.155

18. Degner LF, Kristjanson LJ, Bowman D, et al. Information needs and decisional preferences in women with breast cancer. JAMA. 1997;277 (18):1485-1492. doi:10.1001/jama.1997.03540420081039

19. Keating NL, Landrum MB, Arora NK, et al. Cancer patients' roles in treatment decisions: do characteristics of the decision influence roles? J Clin Oncol. 2010;28(28):4364 4370. doi:10.1200/JCO.2009.26.8870

20. Schattner A, Bronstein A, Jellin N. Information and shared decisionmaking are top patients' priorities. BMC Health Serv Res. 2006;6 (1):21. doi:10.1186/1472-6963-6-21

21. Strull WM. Do patients want to participate in medical decision making? JAMA. 1984;252(21):2990-2994. doi:10.1001/ jama.1984.03350210038026

22. Mossman J, Boudioni M, Slevin ML. Cancer information: a cost-effective intervention. Eur J Cancer. 1999;35(11):1587-1591. doi:10.1016/S0959-8049(99)00195-1
23. Cassileth BR, Zupkis RV, Sutton-Smith K, March V. Information and participation preferences among cancer patients. Ann Int Med. 1980;92(6):832-836. doi:10.7326/0003-4819-92-6-832

24. Fallowfield L, Ford S, Lewis S. No news is not good news: information preferences of patients with cancer. Psychooncology. 1995;4 (3):197-202. doi:10.1002/pon.2960040305

25. Finney Rutten LJ, Arora NK, Bakos AD, Aziz N, Rowland J. Information needs and sources of information among cancer patients: a systematic review of research (1980-2003). Patient Educ Couns. 2005;57(3):250-261. doi:10.1016/j.pec.2004.06.006

26. Vogel BA, Bengel J, Helmes AW. Information and decision making: patients' needs and experiences in the course of breast cancer treatment. Patient Educ Couns. 2008;71(1):79-85. doi:10.1016/j. pec.2007.11.023

27. Sekimoto M, Asai A, Ohnishi M, et al. Patients' preferences for involvement in treatment decision making in Japan. BMC Fam Pract. 2004;5(1):1. doi:10.1186/1471-2296-5-1

28. Okuhara $T$, Ishikawa $H$, Urakubo A, et al. Cancer information needs according to cancer type: a content analysis of data from Japan's largest cancer information website. Preventive Medicine Reports. 2018;12:245-252. doi:10.1016/j.pmedr.2018.10.014

29. Galloway S, Graydon J, Harrison D, et al. Informational needs of women with a recent diagnosis of breast cancer: development and initial testing of a tool. J Adv Nurs. 1997;25:1175-1183. doi:10.1046/ j.1365-2648.1997.19970251175.x

30. Bubela N, Galloway S, McCay E, et al. The Patient Learning Needs Scale: reliability and validity. $J$ Adv Nurs. 1990;15:1181-1187. doi:10.1111/j.1365-2648.1990.tb01711.x

31. Krabbe PFM. Thurstone scaling as a measurement method to quantify subjective health outcomes. Med Care. 2008;46:357-365. doi:10.1097/MLR.0b013e31815ceca9

32. Degner LF, Davison BJ, Sloan JA, Mueller B. Development of a scale to measure information needs in cancer care. J Nurs Meas. 1998;6(2):137-153. doi:10.1891/1061-3749.6.2.137

33. Lipton HL, Byrns PJ, Soumerai SB, Chrischilles EA. Pharmacists as agents of change for rational drug therapy. Int $J$ Technol Assess Health Care. 1995;11(3):485-508. doi:10.1017/S0266462300008692

34. Murray MD, Young J, Hoke S. Pharmacist intervention to improve medication adherence in heart failure: a randomized trial. Ann Int Med. 2007;146:714-725. doi:10.7326/0003-4819-146-10200705150-00005

35. Lam MSH, Cheung N. Impact of oncology pharmacist-managed oral anticancer therapy in patients with chronic myelogenous leukemia. $J$ Oncol Pharm Pract. 2016;22(6):741-748. doi:10.1177/ 1078155215608523

36. Morgado MP, Morgado SR, Mendes LC, Pereira LJ, Castelo-Branco M. Pharmacist interventions to enhance blood pressure control and adherence to antihypertensive therapy: review and meta-analysis. $\mathrm{Am}$ $J$ Health Syst Pharm. 2011;68(3):241-253. doi:10.2146/ajhp090656

37. Bultman DC, Svarstad BL. Effects of pharmacist monitoring on patient satisfaction with antidepressant medication therapy. $J \mathrm{Am}$ Pharm Assoc. 2002;42:36-43.

38. Worley MM, Schommer JC, Brown LM, et al. Pharmacists' and patients' roles in the pharmacist-patient relationship: are pharmacists and patients reading from the same relationship script? Res Social Adm Pharm. 2007;3(1):47-69. doi:10.1016/j.sapharm.2006.03.003

39. Beaver K, Booth K. Information needs and decision-making preferences: comparing findings for gynaecological, breast and colorectal cancer. Eur J Oncol Nurs. 2007;11(5):409-416. doi:10.1016/j.ejon.2007.04.004

40. Beaton DE, Bombardier C, Guillemin F, Ferraz MB. Guidelines for the process of cross-cultural adaptation of self-report measures. Spine. 2000;25(24):3186-3191. doi:10.1097/00007632-200012150-00014

41. Charles C, Gafni A, Whelan T. Shared decision-making in the medical encounter: what does it mean? (or it takes at least two to tango). Soc Sci Med. 1997;44(5):681-692. doi:10.1016/S0277-9536(96) 00221-3 
42. van der Waal MAE, Casparie AF, Lako CJ. Quality of care: a comparison of preferences between medical specialists and patients with chronic diseases. Soc Sci Med. 1996;42:643-649. doi:10.1016/ 0277-9536(95)00200-6

43. Michelson BWH, Nystedt M, Bouland C, Degner LF, Wilking N. Information needs and preferences for participation in treatment decisions among Swedish breast cancer patients. Acta Oncol. 2000;39:467-476. doi:10.1080/028418600750013375

44. Choi KC, So WKW, Li PWC, Lau SF, Lo JCK. Consistency in paired comparisons of Information Needs Questionnaires (INQ) among Hong Kong Chinese breast cancer patients. Eur J Oncol Nurs. 2013;17:170-175. doi:10.1016/j.ejon.2012.04.002
45. Sugano K, Nakamura S, Ando J, et al. Cross-sectional analysis of germline BRCA1 and BRCA2 mutations in Japanese patients suspected to have hereditary breast/ovarian cancer. Cancer Sci. 2008;99:1967-1976.

46. Kawaguchi T, Azuma K, Yamaguchi T, et al. Development and validation of the Japanese version of the Decisional Conflict Scale to investigate the value of pharmacists' information: a before and after study. BMC Med Inform Decis Mak. 2013;13:50. doi:10.1186/ 1472-6947-13-50

47. Kawaguchi T, Azuma K, Yamaguchi T, et al. Preferences for pharmacist counselling in patients with breast cancer: a discrete choice experiment. Biol Pharm Bull. 2014;37:1795-1802.

\section{Publish your work in this journal}

Patient Preference and Adherence is an international, peer-reviewed, open access journal that focusing on the growing importance of patient preference and adherence throughout the therapeutic continuum. Patient satisfaction, acceptability, quality of life, compliance, persistence and their role in developing new therapeutic modalities and compounds to optimize clinical outcomes for existing disease states are major areas of interest for the journal. This journal has been accepted for indexing on PubMed Central. The manuscript management system is completely online and includes a very quick and fair peer-review system, which is all easy to use. Visit http:// www.dovepress.com/testimonials.php to read real quotes from published authors. 